\title{
Thrombocytopenia in the intensive care unit
}

\author{
Zohreh Ostadi ${ }^{1}$, Kamran Shadvar $^{2}$, Sarvin Sanaie ${ }^{3}$, \\ Ata Mahmoodpoor ${ }^{4}$, Seied Hadi Saghaleini ${ }^{5}$
}

\begin{abstract}
Thrombocytopenia is a frequent finding in intensive care unit especially among adults and medical ICU patients. Thrombocytopenia is defined as a platelet count less than $100 \times 10^{9} / \mathrm{l}$ in ICU setting. Platelets are made in the bone marrow from megakaryocytes. Although not fully understood, proplatelets transform into platelets in the lung. The body tries to maintain platelet count relatively constant throughout life. Pathophysiology of thrombocytopenia can be defined by hemodilution, elevated levels of platelet consumption, compromise of platelet production, increased platelet sequestration and increased platelet destruction. Unlike in other situations, absolute platelet count alone does not provide sufficient data in characterizing thrombocytopenia in ICU patients. In such cases, the time course of changes in platelet count is also pivotal. The dynamics of platelet count decrease vary considerably between different ICU patient populations including trauma, major surgery and minor surgery/medical conditions.

There are strong evidences available that delay in platelet count restoration in ICU patients is an indicator of a bad outcome.
\end{abstract}

KEYWORDS: Thrombocytopenia, Intensive care unit, Pathogenesis, Management.

How to cite this:

doi: https://doi.org/10.12669/pjms.35.1.19

Ostadi Z, Shadvar K, Sanaie S, Mahmoodpoor A, Saghaleini SH. Thrombocytopenia in the intensive care unit. Pak J Med Sci. 2019;35(1):282-287. doi: https://doi.org/10.12669/pjms.35.1.19

This is an Open Access article distributed under the terms of the Creative Commons Attribution License (http://creativecommons.org/licenses/by/3.0), which permits unrestricted use, distribution, and reproduction in any medium, provided the original work is properly cited.

1. Zohreh Ostadi,

Anesthesiologist,

2. Kamran Shadvar,

Associate Professor of Anesthesiology,

3. Sarvin Sanaie,

Assistant Professor of Nutrition, MD, PhD,

Tuberculosis and Lung Disease Research Center,

4. Ata Mahmoodpoor,

Professor of Anesthesiology,

5. Seied Hadi Saghaleini,

Assistant Professor of Anesthesiology,

1,2,4,5: Fellowship of Critical Care Medicine, Department of Anesthesiology,

Faculty of Medicine,

1-5: Tabriz University of Medical Sciences,

Tabriz, Iran.

Correspondence:

Seied Hadi Saghaleini,

General ICU, Shohada Hospital,

El-Goli Street,

Tabriz, Iran.

Email: hsaghaleini@gmail.com

* Received for Publication:

November 12, 2018

Revision Received:

November 17, 2018

* $\quad$ Accepted for Publication:

\section{INTRODUCTION}

Thrombocytopenia is a frequent finding in intensive care unit (ICU), with an incidence ranging from 13\% to almost $60 \%$ in different studies. This variability is due to the vulnerability of different patients to thrombocytopenia. For example, it has been shown that thrombocytopenia is more frequent among adults and medical ICU patients in comparison with children and surgical ICU cases. In addition, thrombocytopenia is not apparent at the time of ICU admission in many cases, while it develops in many patients while they stay in the ICU. ${ }^{1,2}$

There is inconsistency regarding the clinical significance of thrombocytopenia in ICU setting. While many authors believe that the emergence of thrombocytopenia in ICU patients could dramatically increase the risk of morbidity and mortality (usually because of an increased risk of bleeding); others suggest that this thrombocytopenia is only an indicator of another more important underlying cause, such as a critical illness or using a particu- 
lar medication. The present article tries to briefly summarize all essential information regarding thrombocytopenia in ICU setting and accordingly increase the level of knowledge and awareness of physicians who deals with ICU patients.

Normal production and activation of platelets: Platelets are made in the human bone marrow from megakaryocytes. Although not fully understood, it has been proposed that proplatelets transform into platelets in the lung after release from the bone-marrow. ${ }^{3}$ The body tries to maintain platelet count relatively constant throughout life. ${ }^{4}$ This regulation is done by secreting thrombopoietin (TPO), a hormone produced by hepatic and renal cells and affects the megakaryocytes to multiply and differentiate to platelets. ${ }^{5}$

The lifespan of a normal platelet is 8-10 days in the blood stream, and almost on third of the total platelet mass is located in the spleen. ${ }^{6}$ When the endovascular lining is injured, the collagen fibrils are exposed to circulating platelets and clot formation is induced after activation of a coagulation cascade. When a platelet is activated, it releases thromboxane A2 and adenosine diphosphate, which in turn attract and activate further platelets. Activated platelets also bind to the glycoprotein $\mathrm{IIb} / \mathrm{III}$ a receptor placed on circulating fibrinogen which induce local aggregations of platelets and fibrin deposition. ${ }^{7}$

Definition and incidence of thrombocytopenia: Thrombocytopenia is defined as a platelet count less than $150 \times 10^{9} / 1$. In ICU setting, the defined cut-off point has been lowered to $100 \times 10^{9} / 1$ by some authors, with $<50 \times 10^{9} / 1$ suggested as severe thrombocytopenia with surgical bleeding. ${ }^{8}$ A spontaneous bleeding usually occurs in patients with a platelet count $<10000 / \mathrm{ml}{ }^{9}$

Unlike in other situations, absolute platelet count alone does not provide sufficient data in characterizing thrombocytopenia in ICU patients. In such cases, the time course of changes in platelet count is also pivotal. For example, a decline more than $50 \%$ compared to the baseline value is considered normal after cardiac surgery, but it is abnormal in the second week of ICU stay. It is also true in patients with no rise in platelet count within five days after ICU admission. So, it is essential to use both absolute platelet count and its changes during ICU stay to define thrombocytopenia. ${ }^{10}$

As stated before, the incidence of thrombocytopenia in ICU patients ranges between $13 \%$ and $60 \%$ in various studies, ${ }^{1,2}$ around $20 \%$ in medical ICU patients, ${ }^{11} 35 \%$ in surgical ICU patients, ${ }^{12}$ and $45 \%$ in trauma ICU patients. ${ }^{13}$

Pathophysiology and etiologies of thrombocytopenia: Pathophysiology of thrombocytopenia, in general, can be defined by five mechanisms: hemodilution, ${ }^{14}$ elevated levels of platelet consumption, ${ }^{15}$ compromise of platelet production, ${ }^{16}$ increased platelet sequestration, ${ }^{17}$ and increased platelet destruction. The first two mechanisms are considered as the major etiologies of thrombocytopenia in ICU patients. ${ }^{10,18}$ (Table-I).

Another important issue in evaluation of thrombocytopenia in ICU patients is the possibility

Table-I: Mechanisms of thrombocytopenia.

\begin{tabular}{|c|c|c|}
\hline Mechanism & Example & Description \\
\hline Hemodilution & & $\begin{array}{l}\text { Massive transfusions of } \\
\text { blood products due to } \\
\text { massive hemorrhage }\end{array}$ \\
\hline Increased platelet consumption & DIC, TTP, HELP syndrome & \\
\hline Decreased platelet production & $\begin{array}{l}\text { Chemotherapy, radiotherapy, cancer, transient } \\
\text { viral infections (mumps, rubella, varicella), chronic } \\
\text { infections (chronic hepatitis C infection, HIV infection), } \\
\text { alcohol abuse, sepsis, drugs, malnutrition, storage } \\
\text { disorders, decreased thrombopoietin }\end{array}$ & $\begin{array}{l}\text { Bone marrow failure or } \\
\text { disease, miscellaneous }\end{array}$ \\
\hline Increased platelet sequestration & $\begin{array}{l}\text { Cirrhosis, portal hypertension, polycythemia vera, } \\
\text { infections, congestive heart failure }\end{array}$ & $\begin{array}{l}\text { Because of } \\
\text { splenomegaly }\end{array}$ \\
\hline Increased platelet destruction & $\begin{array}{l}\text { HIT, ITP, mechanical devices, microangiopathies, } \\
\text { drugs, splenomegaly, sepsis }\end{array}$ & $\begin{array}{l}\text { Immune-mediated, } \\
\text { miscellaneous }\end{array}$ \\
\hline
\end{tabular}

DIC: disseminated intravenous coagulopathy, HELP: hemolysis, elevated liver enzymes, low platelets,

HIT: heparin-induced thrombocytopenia, HIV: human immunodeficiency virus,

ITP: idiopathic thrombocytopenic purpura, TTP: thrombotic thrombocytopenic purpura. 
Table-II: Important drugs contributing to thrombocytopenia in ICU patient population.

\begin{tabular}{ll}
\hline Name & Possible mechanism (s) \\
\hline Aspirin & $\begin{array}{l}\text { Inhibits cyclooxygenase 1, blocks thromboxane A2 production, disrupts } \\
\text { platelet aggregation } \\
\text { Nonsteroidal anti-inflammatory drugs }\end{array}$ \\
$\begin{array}{l}\text { Inhibit cyclooxygenase 1 } \\
\text { Blocks glycoprotein IIb/IIIareceptor, induces thrombotic } \\
\text { thrombocytopenic purpura }\end{array}$ \\
$\begin{array}{l}\text { Dipyridamole and ticlopidine } \\
\text { Abciximab }\end{array}$ & $\begin{array}{l}\text { Glycoprotein IIb/IIIa receptor antagonist } \\
\text { Eptifibatide }\end{array}$ \\
$\begin{array}{l}\text { Glycoprotein IIb/IIIa receptor antagonist, displaces fibrinogen from } \\
\text { activated glycoprotein IIb/IIIa receptors, facilitates dispersal of platelet }\end{array}$ \\
$\begin{array}{l}\text { Antibiotics (trimethoprim/ } \\
\text { sulfamethoxazole, blactam antibiotics, } \\
\text { vancomycin, linezolid) }\end{array}$ & Unknown, miscellaneous \\
$\begin{array}{l}\text { Anticonvulsive drugs (phenytoin, } \\
\text { carbamazepine, valproate, } \\
\text { phenobarbital) } \\
\text { Antihistamines (ranitidine) }\end{array}$ & Unknown, miscellaneous \\
\hline
\end{tabular}

of pseudothrombocytopenia. Using medications with glycoprotein IIb/IIIa antagonistic properties such as abciximab, integrilin or tirofiban may also contribute to this condition. In such cases, platelet aggregates are present in peripheral blood smears. ${ }^{19}$ Repeated blood counts in citrated or heparinized blood could rule out idiopathic pseudothrombocytopenia. ${ }^{20}$

Various etiologies may underlie the occurrence of thrombocytopenia in ICU patients, including drug exposure (Table-II), intravascular devices (such as pulmonary artery catheters, intra-aortic balloon pumps, central venous catheter), higher severity of illness score in ICU admission, ${ }^{21}$ sepsis, and hypothermia. ${ }^{22}$

Dynamics of normal platelet count decrease in ICU patients: The dynamics of platelet count decrease vary considerably between different ICU patient populations including trauma, major surgery and minor surgery/medical conditions. ${ }^{10}$

In major postsurgical cases a nadir is typically seen between day one and day four. This decrease is usually due to platelet consumption and correlates significantly with the extent of tissue injury and blood loss. In normal conditions, the platelet count reaches back to a normal level two weeks after surgery. ${ }^{23}$ In abdominal surgery patients, however, the nadir occurs earlier (day 1-2) and the recovery is faster (day 3-4). ${ }^{24}$

In traumatic cases with critical injuries, the admission platelet count is usually normal and a rapid platelet count decrease happens within hours after hospitalization. ${ }^{25}$ A low platelet count at admission, and delay in recovery during ICU stay has been regarded as an ominous sign. ${ }^{26}$

In medical patients, the dynamics of platelet count changes depend greatly on the underlying condition. For example, sepsis, endocarditis, leukemia, thromboembolism, chronic infections, alcohol intoxication, using intravascular devices, renal replacement therapy, employment of extracorporeal circuits, disseminated intravenous coagulopathy (DIC), multiorgan failure and late cardiopulmonary resuscitations are in essence associated with thrombocytopenia. ${ }^{27-30}$

Generally, any rapid decrease in platelet count within 24-48 hours after ICU admission in any population, or when a platelet count increment is less than $5000 / \mathrm{ml}$ one-hour post transfusion (refractoriness) an immune-mediated process that destroy transfused platelets rapidly (such as ITP, alloimmunization, heparin or any other druginduced immune thrombocytopenia) is suggested, whereas a gradual decline indicates marrow suppression of thrombopoiesis or subacute platelet consumption. ${ }^{27}$

The nadir in drug-induced thrombocytopenia is typically less than $10000 / \mu \mathrm{l}$, while in heparininduced cases the nadir is usually more than 20000-50000/ $\mu$ l. Table-III summarizes differential diagnosis of thrombocytopenia in ICU patients.

DIT/HIT: Drug-induced thrombocytopenia in 
Table-III: Differential diagnosis of thrombocytopenia in the ICU.

\begin{tabular}{ll}
\hline Differential diagnosis & Findings \\
\hline Sepsis & $\begin{array}{l}\text { Presence of dedicated criteria such as positive cultures and } \\
\text { clinical findings }\end{array}$ \\
Disseminated intravascular coagulation & Abnormal laboratory findings \\
Massive blood loss & Abnormal laboratory findings, bleeding \\
Thrombotic microangiopathy & Schistocytes in blood examination, clinical findings \\
Heparin-induced thrombocytopenia & A positive history of heparin use, laboratory findings \\
Immune thrombocytopenia & Immunological and laboratory findings \\
Drug-induced thrombocytopenia & Abnormal findings in bone aspiration, immunological and \\
\hline
\end{tabular}

ICU patients can be divided as non-immune (such as histamine $\mathrm{H}_{2}$ antagonists, nonsteroidal antiinflammatory drugs,) and immune (such as IIb/ IIIa inhibitors, trimethoprim/sulfamethoxazole, vancomycin, penicillin, ceftriaxone, mirtazapine, ibuprofen and unfractionated heparin) categories. ${ }^{30}$ Heparin-induced thrombocytopenia (HIT) is caused by the development of IgG antibodies directed against a complex of platelet factor 4 (PF4) and heparin ${ }^{31}$ and presenting with more than a half of the baseline platelet count, to $50-80 \times 10^{9} / \mathrm{L}$ or a new thrombosis occurring 5-14 days after heparin initiation. ${ }^{30}$ Table-IV shows $4 \mathrm{~T}$ score for prediction of HIT in critically ill patients.

Management of thrombocytopenia in different ICU settings: In trauma cases, coagulopathy is due to a mixture of underlying pathologies such as accelerated platelet/clotting factors consumption, hemodilution, metabolic abnormalities, hypothermia, etc. that need to be corrected concomitantly.
Early administration of plasma, platelet and red blood cells has been found vital in a recent study. ${ }^{32}$ Using antifibrinolytic agents such as tranexamic acid is also suggested in severe trauma patients. ${ }^{33}$ When DIC is present, platelet transfusion should be reserved for cases with active bleeding and in those who are diagnosed as very high risk for bleeding. ${ }^{34}$ In septic patients there is a controversy in transfusing platelet. ${ }^{35}$ Bone marrow suppression is usually along with pancytopenia rather than an isolated thrombocytopenia that rarely develops independently in ICU patients because of an unrecognized comorbidity such as malignancy, infection, osteoporosis, myelofibrosis, etc. ${ }^{10,36-37}$ Specific treatments such as charcoal ingestion, dialysis and specific antidote use are necessary. ${ }^{38}$ Early plasma exchange with or without corticosteroid/rituximab administration is indicated in such patients. ${ }^{39}$ Hemolytic-uremic syndrome (HUS) should be managed by using monoclonal humanized anti-

Table-IV: 4T score for prediction of HIT in critically ill patients.

\begin{tabular}{|c|c|c|c|}
\hline Points* & 2 & 1 & 0 \\
\hline Thrombocytopenia & $\begin{array}{l}>50 \% \text { fall andplatelet minimum } \\
\geq 20 \times 10^{9} / 1\end{array}$ & $\begin{array}{l}30-50 \% \text { fall or platelet } \\
\text { minimum } 10-19 \times 10^{9} / 1\end{array}$ & $\begin{array}{l}\text { Fall }<30 \% \text { or platelet } \\
\text { minimum }<10 \times 10^{9} / 1\end{array}$ \\
\hline $\begin{array}{l}\text { Timing** of platelet } \\
\text { count fall or other } \\
\text { sequelae }\end{array}$ & $\begin{array}{l}\text { Clear onset between days } 5 \text { and } \\
10 \text {; or } \leq 1 \mathrm{~d} \text { (if heparinexposure } \\
\text { within past } 30 \mathrm{~d} \text { ) }\end{array}$ & $\begin{array}{l}\text { Consistent with immunization } \\
\text { but not clear or onset of } \\
\text { thrombocytopenia after day } \\
10 \text {; or fall } \leq 1 \mathrm{~d} \text { (if heparin } \\
\text { exposure30-100 d ago) }\end{array}$ & $\begin{array}{l}\text { Platelet count fall } \leq 4 \\
\mathrm{~d} \text { (without recent heparin } \\
\text { exposure) }\end{array}$ \\
\hline $\begin{array}{l}\text { Thrombosis or other } \\
\text { sequelae }\end{array}$ & $\begin{array}{l}\text { New thrombosis; skin necrosis; } \\
\text { post- heparin bolus acute } \\
\text { systemic reaction }\end{array}$ & $\begin{array}{l}\text { Progressive or recurrent } \\
\text { thrombosis; erythematous } \\
\text { skin lesions; suspected } \\
\text { thrombosis not yet proven }\end{array}$ & None \\
\hline $\begin{array}{l}\text { Other cause for throm- } \\
\text { bocytopenia not evident }\end{array}$ & No other cause is evident & Possible other cause is evident & $\begin{array}{l}\text { Definite other cause is } \\
\text { present }\end{array}$ \\
\hline
\end{tabular}

*(0,1, or 2 for each category; maximum score $=8)$. Pretest probability score: $6-8=$ High; $4-5=$ Intermediate; $0-3=$ Low . **First day of immunizing heparin exposure considered day 0 ; the day the platelet count begins to fall is considered the day of onset of thrombocytopenia 
Table-V: Treatment recommendations for patients with HIT.

- Clinical decisions should be made following consideration of the risks and benefits of treatment with an alternative anticoagulant

- For patients with suspected or confirmed HIT, heparin should be stopped and full dose anticoagulation with an alternative anticoagulant commenced

- LMWH should not be used in the treatment of HIT

- Warfarin should not be used until the platelet count has recovered to the normal range. When introduced, an alternative anticoagulant must be continued until the INR is therapeutic. Argatroban affects the INR and this needs to be considered when using this drug. A minimum overlap of $5 \mathrm{~d}$ between non-heparin anticoagulants and VKA therapy is recommended

- Platelets should not be given for prophylaxis but may be used in the event of bleeding

- If the patient has received a VKA at the time of diagnosis it should be reversed by administering intravenous vitamin $\mathrm{K}$

C5 antibody, eculizumab andimmunoadsorption. ${ }^{37}$ Antiphospholipid syndrome may be present in ICU patients and should be managed by anticoagulation, platelet inhabitation, plasma exchange, immunoadsorption, corticosteroids, and intravenous immunoglobulins. ${ }^{38}$ Long-term immunosuppression with cyclophosphamide or rituximab and eculizumab may also be necessary. ${ }^{38}$ If sever bleeding is present, intravenous immunoglobulin $(1 \mathrm{~g} / \mathrm{kg}$ for 2 days) and platelet transfusion are indicated. In case of a definite diagnosis, heparin use should be ceased and replaced by an alternative non-heparin anticoagulant, platelet count monitoring should be performed every two or three days from day four to day 14, platelets should not be given for prophylaxis but may be used in the event of bleeding, patients should be therapeutically anticoagulated for 3 months after HIT with a thrombotic complication and for 4 weeks following HIT without a thrombotic complication. ${ }^{39}$ Table-V shows treatment recommendations for patients with HIT.

Platelet transfusion: There is no fixed platelet count threshold in ICU patients that signals platelet transfusion, ${ }^{32}$ but because of hemorrhage fear there is a widespread notion that the platelet count should be maintained over $100 \times 10^{9} / \mathrm{L}$ in massive bleeding or when bleeding occurs at dangerous sites such as in intracranial hemorrhage. ${ }^{33}$

In addition to platelet count, the risk of hemorrhage is also dependent on the hematocrit and the bleeding time. ${ }^{34}$ So, red blood cell transfusion should also be considered as a part of a supportive therapy, if needed. ${ }^{10}$

Despite these recommendations, it should be born in mind that platelet transfusion is not a riskfree procedure and may cause several potentially fatal complications such as contamination, allergic reactions, venous thromboembolism and transfusion-related acute lung injury (TRALI). ${ }^{35}$ Another problem in ICU patients is bleeding in connection with antiplatelet drug use. In such cases, platelet transfusion is usually considered as an antidote, but circulating metabolites of antiplatelet drugs inhibit transfused platelets, either. ${ }^{36}$

An efficient platelet transfusion in ICU setting could be judged by cessation/reduction of clinical bleeding. Unlike in non-ICU patients, this judgment might be very difficult in ICU cases because of the complexity of patients' condition owing to the presence of a myriad of concomitant cofactors that could be hardly controlled. ${ }^{10}$ Factors that negatively affect the increase in platelet count after platelet transfusions are using stored platelets for a long-term, fever/infection, and presence of splenomegaly in the recipient. ${ }^{40}$

Prognosis of thrombocytopenia in ICU: It has been shown that the development of thrombocytopenia during an ICU admission significantly increases morbidity and mortality. ${ }^{41}$ According to these information, morbidity and mortality rates have been more striking in patients who develops thrombocytopenia after ICU admission compared to patients whose platelet count is normalized or remains stable within the first week of ICU stay. The prognosis has been found even worse in patients whose thrombocytopenia worsened or not resolved beyond the first four to seven days of ICU admission.

Conflict of interest: The Authors declare no conflict of interest.

\section{REFERENCES}

1. Hui P, Cook DJ, Lim W, Fraser GA, Arnold DM. The frequency \& clinical significance of thrombocytopenia complicating critical illness: A systematic review. Chest. 2011;139(2):271-278. doi:10.1378/chest.10-2243.

2. Priziola JL, Smythe MA, Dager WE. Drug-induced thrombocytopenia in critically ill patients. Crit Care Med. 2010;38(6 Suppl):S145-S154. doi: 10.1097/CCM. 0b013e3181de0b88. 
3. Trowbridge EA, Martin JF, Slater DN. Evidence for a theory of physical fragmentation of megakaryocytes, implying that all platelets are produced in the pulmonary circulation. Thromb Res. 1982;28(4):461-475. doi:10.1016/0049-3848(82)90163-3

4. Bessman JD, Williams LJ, Gilmer PR, Jr. Mean platelet volume. The inverse relation of platelet size and count in normal subjects, and an artifact of other particles. Am J Clin Pathol. 1981;76(3):289-293.

5. Wang HL, Aguilera C, Knopf KB, Chen TM, Maslove DM, Kuschner WG. Thrombocytopenia in the intensive care unit. J Intensive Care Med. 2013;28(5):268-280. doi: 10.1177/0885066611431551.

6. Alberio L, Friese P, Clemetson KJ, Dale GL. Collagen response and glycoprotein VI function decline progressively as canine platelets age in vivo. Thromb Haemost. 2002;88(3):510-516.

7. Jackson SP. The growing complexity of platelet aggregation. Blood. 2007;109(12):5087-5095. doi: 10.1182/blood-2006-12-027698.

8. Stanworth SJ, Walsh TS, Prescott RJ, Lee RJ, Watson DM, Wyncoll DL, et al. Thrombocytopenia and platelet transfusion in UK critical care: a multicenter observational study. Transfusion. 2013;53(5):10501058. doi:10.1111/j.1537-2995.2012.03866.x.

9. Slichter SJ, Kaufman RM, Assmann SF, McCullough J, Triulzi DJ, Strauss RG, et al. Dose of prophylactic platelet transfusions and prevention of hemorrhage. N Engl J Med. 2010;362(7):600-613. doi :10.1056/ NEJMoa0904084.

10. Thiele T, Selleng K, Selleng S, Greinacher A, Bakchoul T. Thrombocytopenia in the intensive care unit-diagnostic approach \& management. Semin Hematol. 2013;50(3):239-250. doi: 10.1053/j. seminhematol.2013.06.008.

11. Crowther MA, Cook DJ, Meade MO, Griffith LE, Guyatt GH, Arnold DM, et al. Thrombocytopenia in medical-surgical critically ill patients: prevalence, incidence, and risk factors. J Crit Care. 2005;20(4):348-353. doi:10.1016/j.jcrc.2005.09.008.

12. Stephan F, Hollande J, Richard O, Cheffi A, Maier-Redelsperger M, Flahault A. Thrombocytopenia in a surgical ICU. Chest. 1999;115(5):1363-1370.

13. Hanes SD, Quarles DA, Boucher BA. Incidence \& risk factors of thrombocytopenia in critically ill trauma patients. Ann Pharmacother. 1997;31(3):285-289.

14. Leslie SD, Toy PT. Laboratory hemostatic abnormalities in massively transfused patients given red blood cells and crystalloid. Am J Clin Pathol. 1991;96(6):770-773.

15. Levi M, Toh CH, Thachil J, Watson HG. Guidelines for the diagnosis and management of disseminated intravascular coagulation. British Committee for Standards in Haematology. Br J Haematol. 2009;145(1):24-33. doi: 10.1111/j.1365-2141.2009.07600.x.

16. Zucker-Franklin D, Cao YZ Megakaryocytes of human immunodeficiency virus-infected individuals express viral RNA. Proceedings of the National Academy of Sciences of the United States of America. 1989;86(14):5595-5599.

17. O'Reilly RA. Splenomegaly in 2,505 patients at a large university medical center from 1913 to 1995.1963 to $1995: 449$ patients. West J Med. 1998;169(2):88-97.

18. Parker RI. Etiology and significance of thrombocytopenia in critically ill patients. Crit Care Clin. 2012;28(3):399-411. doi:10.1016/j. ccc.2012.04.007.

19. Bain BJ. Diagnosis from the blood smear. N Engl J Med. 2005;353(5):498-507. doi:10.1056/NEJMra043442.

20. Lippi G, Plebani M. EDTA-dependent pseudothrombocytopenia: further insights and recommendations for prevention of a clinically threatening artifact. Clin Chem Lab Med. 2012;50(8):1281-1285. doi:10.1515/cclm-2012-0081.

21. Bose S, Wurm E, Popovich MJ, Silver BJ. Drug-induced immunemediated thrombocytopenia in the intensive care unit. J Clin Anesth. 2015;27(7):602-605. doi: 10.1016/j.jclinane.2015.06.021.

22. Vanderschueren S, De Weerdt A, Malbrain M, Vankersschaever D, Frans E, Wilmer A, eta 1. Thrombocytopenia and prognosis in intensive care. Crit Care Med. 2000;28(6):1871-1876.

23. Selleng S, Malowsky B, Strobel U, Wessel A, Ittermann T, Wollert $\mathrm{HG}$, et al. Early-onset and persisting thrombocytopenia in post-cardiac surgery patients is rarely due to heparin-induced thrombocytopenia, even when antibody tests are positive. J Thromb Haemost. 2010;8(1):30-36. doi:10.1111/j.1538-7836.2009.03626.x.

24. Nijsten MW, ten Duis HJ, Zijlstra JG, Porte RJ, Zwaveling JH, Paling $\mathrm{JC}$, et al. Blunted rise in platelet count in critically ill patients is associated with worse outcome. Crit Care Med. 2000;28(12):3843-3846.

25. Stansbury LG, Hess AS, Thompson K, Kramer B, Scalea TM, Hess JR. The clinical significance of plateletcounts in thefirst 24 hours after severe injury. Transfusion. 2013;53(4):783-789. doi:10.1111/j.1537-2995.2012.03828.
26. Floccard B, Rugeri L, Faure A, Saint Denis M, Boyle EM, Peguet O, et al Early coagulopathy in trauma patients: An on-scene \& hospital admission study. Injury. 2012;43(1):26-32. doi:10.1186/s13063-017-1980-x.

27. Rice TW, Wheeler AP. Coagulopathy in critically ill patients: part 1: platelet disorders. Chest. 2009;136(6):1622-1630. doi:10.1378/ chest.08-2534.

28. Mahmoodpoor A, Peyrovi-far A, Hamishehkar H, Bakhtyiari Z, Mirinezhad MM, Hamidi M, et al. Comparison of prophylactic effects of polyurethane cylindrical or tapered cuff and polyvinyl chloride cuff endotracheal tubes on ventilator-associated pneumonia. Acta Med Iran. 2013;51(7):461-466.

29. Peirovifar A, Eydi M, Mirinejhad MM, Mahmoodpoor A, Mohammadi A, Golzari SE. Comparison of postoperative complication between Laryngeal Mask Airway and endotracheal tube during low-flow anesthesia with controlled ventilation. Pak J Med Sci. 2013;29(2):601-605

30. Najafi A, Mojtahedzadeh M, Mahmoodpoor A, Aghamohammadi M, Ahmadi A, Nahreini S, et al. Effect of N-Acetylcysteine on microalbuminoria in patients with acute respiratory distress syndrome. Arch Med Sci. 2009;5(3):408-414.

31. Henry Watson, Simon Davidson, David Keeling. Guidelines on the diagnosis and management of heparin induced thrombocytopenia: second edition. Br J Haematol. 2012;159(5):528-540. doi: 10.1111/ bjh.12059.

32. Hunt BJ. Bleeding and coagulopathies in critical care. N Engl J Med. 2014;370(9):847-859. doi:10.1056/NEJMra1208626.

33. Pene F, Benoit DD. Thrombocytopenia in the critically ill: considering pathophysiology rather than looking for a magic threshold. Intensive Care Med. 2013;39(9):1656-1659. doi:10.1186/s13613-015-0088-2.

34. Kitchens CS. Thrombocytopenia and thrombosis in disseminated intravascular coagulation (DIC). Hematology Am Soc Hematol Educ Program. 2009;1:240-246. doi:10.1182/ asheducation-2009.1.240.

35. Tabeefar H, Beigmohammadi MT, Javadi MR, Abdollahi M, Mahmoodpoor A, Ahmadi A, et al. Effects of Pantoprazole on Systemic and Gastric Pro- and Anti-inflammatory Cytokines in Critically Ill Patients. Iran J Pharm Res. 2012;11(4):1051-1058.

36. Hamishehkar H, Beigmohammadi MT, Abdollahi M, Ahmadi A, Mahmoodpour A, Mirjalili MR, et al. Identification of enhanced cytokine generation following sepsis. Dream of magic bullet for mortality prediction and therapeutic evaluation. Daru. 2010;18(3):155-162.

37. Martin CM, Priestap F, Fisher H, Fowler RA, Heyland DK, Keenan $\mathrm{SP}$, et al. A prospective, observational registry of patients with severe sepsis: the Canadian Sepsis Treatment and Response Registry. Crit Care Med. 2009;37(1):81-88. doi:10.1097/CCM.0b013e31819285f0.

38. Asherson RA, Cervera R, de Groot PG, Erkan D, Boffa MC, Piette JC, et al. Catastrophic antiphospholipid syndrome: international consensus statement on classification criteria and treatment guidelines. Lupus. 2003;12(7):530-534. doi:10.1191/ 0961203303lu394oa.

39. Greinacher A, Selleng K. Thrombocytopenia in the intensive care unit patient. Hematology Am Soc Hematol Educ Program. 2010;2010:135 143. doi:10.1182/asheducation-2017.1.660.

40. Ahmed I, Majeed A, Powell R. The management of heparin-induced thrombocytopenia. Br J Haematol. 2006;133(3):259-269. doi:10.1136/ pgmi.2007.059188.

41. Trehel-Tursis V, Louvain-Quintard V, Zarrouki Y, Imbert A, Doubine $\mathrm{S}$, Stephan F. Clinical and biologic features of patients suspected or confirmed to have heparin-induced thrombocytopenia in cardiothoracic surgical ICU. Chest 2012;142(4):837-844. doi:10.1378/ chest.11-3074.

\section{Author's Contribution:}

ZO: Literature review, writing the initial draft of the manuscript and approving final version.

KSh: Literature review and approving final version. SS: Drawing tables, editing language and approving final version.

AM: Concept of manuscript, Literature review, editing and approving final version.

SHS: Literature review and approving final version. 